\title{
ANALISIS KINERJA GURU PAI DALAIM PENERAPAN METODE PROMPTS PADA PENYANDANG DISABILITAS DI SLB A YAPTI MAKASSAR
}

\author{
Nur Aliah Ali, Novalia Tanasy \\ Fakultas Keguruan dan Ilmu Pendidikan \\ Universitas Muslim Maros \\ Email: alyaery@umma.ac.id
}

\begin{abstract}
This study is aim to determine the ability and skills of Islamic education teachers in applying prompts methods for students with disabilities A or blind students.The specific purpose is to find out the performance of the Islamic education teacher in applying thetypes of prompts in the form ofverbal prompts, gestural prompts, modeling prompts and physical prompts, beside that this study is determine too the factors that influence the performance of Islamic education teachers in applying the prompts method to students with disabilities A in SLB A YAPTI Makassar especiallyfor the subject Thaharah, Prayer and Read and write the Qur'an.

The research method used is field research with descriptive qualitative and quantitative analysis. In this study, the data collection methods used are observation, interviews, and documentation. The collected data will be analyzed usingan interactive model of Mile and Huberman which includes data reduction, data presentation, verification and conclusion drawing. The type of qualitative data will be analiyzed by deductive-inductive conclusions and quantitative data analyzed using descriptive quantitative in the form of percentages and performance scoring based on the performance scoring table.

The research results obtained areThe teacher's performance level are at varying levels. namely moderate, high and very high. NH teachers have a performance at a score of 4 or very high level which means applying all types of prompts in Islamic learning process. RM teachers have a performance at a score of 3 or high level that applies 3 prompts while the KS teacher is on a score of 2 or medium level which only applies two types of prompts namely verbal and physical prompts only. Differences The use of types and indicators applied by Islamic education teachers is different due to material factor, student and teacher characteristics factors.
\end{abstract}

Keywords: Teacher Performance, Prompts Method, Disabilities A.

\section{PENDAHULUAN}

$\mathrm{P}$ enyandang disabilitas memiliki hak untuk mendapatkan pendidikan yang bermutu pada satuan pendidikan di semua jenis, jalur, dan jenjang pendidikan secara inklusif dan khusus. Penyandang disabilitasmerupakan orang yang mempunyai keterbatasan mental, fisik, intelektual maupun sensorik yang dialami dalam jangka waktu lama sehingga menyulitkan mereka dalam berpartisipasi penuh dan efektif.Berkaitan dengan proses pendidikan akan lebih sulit mengajari siswa yang memiliki kelainan fisik 
terutama bagi siswa tunanetra. Menurut Somantri anak tunanetra merupakanindividu yang indera penglihatannya (kedua-duanya) tidak bisa digunakan sebagai saluran penerima informasi dalam kegiatan sehari-hari secara optimal seperti halnya orang awas. ${ }^{1}$

Mendidik anak tunanetra tidak sama seperti mendidik anak normal karena memerlukan pendekatan dan strategi yang khusus, agar pesan atau materi pelajaran yang disampaikan dapat diterima /dicerna oleh anak tunanetra melalui indera-indera yang masih berfungsi, yaitu indera pendengaran, perabaan, serta sisa penglihatan bagi anak low vision.

Salah satu strategi yang dapat digunakan pada siswa penyandang disabilitas A yaitu penerapan metode prompts. Metode prompts merupakan stimulus yang diberikan sebelum atau selama terjadinya perilaku. Prompts berfungsi membantu terjadinya perilaku yang diinginkan, sehingga siapapun yang melakukan perilaku tersebut bisa memperoleh penguatan dari guru atau konselor. Bagi siswa penyandang disabilitas A yang memiliki keterbatasan dalam penglihatan, metode verbal, Gestural, modeling, dan phisiscal prompts yang memberikan bantuan berupa sentuhan dan perabaan fisik, sangatlah membantu mereka mereka dalam menerima pembelajaran tidak terkecuali pada pembelajaran PendidikanAgama Islam (PAI).

Pendidikan Agama Islam merupakan tuntunan dan pedoman hidup yang dapat diimplementasikan dalam kehidupan sehari-hari guna mendapatkan keselamatan dan kebahagiaan di dunia dan di akhirat kelak. Oleh Karena itu sangat penting bagi siswa tunanetra untuk mengetahui, memahami dan melaksanakan ajaran Islam secara utuh dan baik.Menilai pentingnya pembelajaran Agama Islam untuk dipahami oleh peserta didik penyandang disabilitas maka dalam pelaksanaan pembelajarannya, seorang guru dituntut untuk mengoptimalkan kinerjanya dalam usaha membantu peserta didik sehingga dapat menerima, memahami dan mencerna materi pembelajaran PAI yang diberikan. Memiliki kinerja yang baik dalam mengelola pembelajaran merupakan hal yang penting, sebagaimana firman Allah SWT dalam surah an Nahl ayat 125 yaitu:

Terjemahnya:

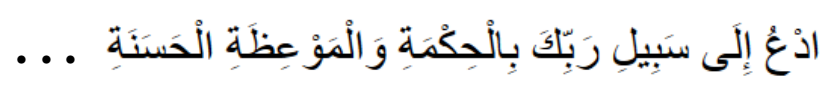

"Ajaklah kepada jalan Tuhan mu dengan bijak dan pengajaran yang baik, dan bantalah (berdiskusilah) dengan mereka dengan cara yang baik ..."2

Sekolah Luar Biasa bagian A (SLB A) YAPTI Makassar merupakan sekolah yang dijadikan penulis sebagai lokasi penelitian. Penelitian dilakukan pada Guru Pendidikan Agama Islam yang berjumlah 3 Orang dan Siswa-siswi SLB A YAPTI Makassar. Berdasar pada observasi awal dan wawancara, peneliti memiliki dugaan sementara bahwa perihal penerapan metode prompts dalam pembelajaran PAI diduga kinerja guru belum terlaksana secara optimal karena berbagai faktor seperti keterbatasan pengetahuan dan

\footnotetext{
${ }^{1}$ Somantri Sutjihati,Psikologi Anak Luar Biasa,(Bandung: PT Refika Aditama, 2012), h. 65.

${ }^{2}$ Departemen Agama RI, Alquran dan Terjemahnya, (Jakarta: Institut Ilmu al Qur'an), h. 281.
} 
keterampilan guru PAI, alat dan media khusus bagi siswa penyandang disabilitas A.Berdasarkan uraian latarbelakang yang dikemukakan, maka penulis tertarik melakukan penelitian dengan judul Analisis Kinerja Guru PAI dalam Penerapan Metode Prompts pada Siswa Penyandang Disabilitas A di SLB A YAPTI Makassar.

Berdasarkan uraian di atas, adapun permasalahan yang menjadi fokus dalam tulisan ini ialah:

1. Mengetahui kinerja guru PAI dalam penerapan metode promptspada siswa penyandang disabilitas A di SLB A YAPTI Makassar?

2. Mengetahui Faktor-faktor yang mempengaruhi kinerja guru PAI dalam penerapan metode prompts pada siswa penyandang disabilitas A SLB A YAPTI Makassar?

\section{METODE PENELITIAN}

\section{A. Desain dan Jenis Penelitian}

Jenis penelitian ini merupakan penelitian lapangan dengan menggunakan analisis kualitatif dan kuantitatif deskriptif. Penelitian kualitatif deskriptif yaitu prosedur penelitian menghasilkan data deskriptif berupa kata-kata tertulis atau lisan dari orangorang dan perilaku yang dapat diamati. Sedangkan kuantitatif deskriptif yaitu prosedur penelitian yang menghasilkan data berupa prosentase dan penskoran kinerja yang selanjutnya akan dideskripsikan secara kualitatif.

\section{B. Teknik Pengumpulan Data}

Tehnik pengumpulan data yang digunakan dalam penelitian ini adalah Observasi, wawancara, praktikum, dan dokumentasi. Obeservasi dilakukan dengan memberikan tanda pada kolom tertentu sebagai instrumen pengamatan dalam penggunaan metode prompts. Wawancara dilakukan menggunakan pedoman wawancara padaGuru PAI dan siswa SLB A YAPTI Makassar. Dokumentasi berupa dokumen berkaitan dengan kinerja guru bahan ajar guru, alat dan media pembelajaran, foto, video, buku-buku, dokumen, catatan harian, dan sebagainya.

\section{Teknik Analisis Data}

Analisis Data dalam penelitian ini dilakukan dengan menggunakan analisis data model interaktif dari Mile dan Huberman yang melalui tahapan yaitu collection, reduction, display dan verification. Pengumpulan data dilakukan dengan dua cara yaitu pengambilan data secara langsung dan melalui alat penelitian. Bentuk data yang diperoleh secara langsung berupa data observasi dan wawancara. Pengambilan data dengan alat yaitu data yang direkam melalui alat berupa kamera atau recorder yang datanya berbentuk Audio, visual dan audio visual.Selanjutnya Pengolahan data dilakukan setelah semua data terkumpul kemudian dilakukan analisis kualitatif dan kuantitatif deskriptif. Penskoran kinerja diperoleh dari data penggunaan prompting yang diterapkan guru PAI yang diolah berdasarkan tabel skoring berikut: 
Tabel 1. Skoring kinerja prompts

\begin{tabular}{l|c|c}
\multicolumn{1}{c|}{ Pemberian Prompts } & Skor & Tingkat \\
\hline \hline All Prompts & 4 & Sangat Tinggi \\
\hline Verbal Prompt + 2 prompts (Physical/ Modeling/ Gestural) & 3 & Tinggi \\
\hline Verbal Prompts +1 prompts(Physical/ Modeling/ Gestural) & 2 & Sedang \\
\hline Verbal Prompt & 1 & Rendah \\
\hline No Prompt & 0 & Sangat Rendah \\
\hline
\end{tabular}

\section{HASIL DAN PEMBAHASAN PENELITIAN}

\section{A. Kinerja Guru PAI}

Riduwan menyatakan kinerja adalah prestasi yang dapat dicapai seseorang atau organisasi berdasarkan kriteria dan alat ukur tertentu ${ }^{3}$. Dessler menyatakan kinerja hampir sama dengan prestasi kerja ialah perbandingan antara hasil kerja aktual dengan standar kerja yang ditetapkan. ${ }^{4}$ Kinerja guru dapat dilihat dan diukur berdasarkan spesifikasi atau kriteria kompetensi yang harus dimiliki oleh setiap guru. Sahertian sebagaimana dikutip Kusmianto menjelaskan bahwa: "Standar kinerja guru itu berhubungan dengan kualitas guru dalam menjalankan tugasnya sepertibekerja dengan siswa secara individual, persiapan dan perencanaan pembelajaran, pendayagunaan media pembelajaran. ${ }^{5}$ Pendapat lain diutarakan Soedijarto menyatakan ada empat tugas gugusan kemampuan yang harus dikuasai oleh seorang guru yaitu: merencanakan program, melaksanakan dan memimpin , menilai kemajuan proses, membina hubungan dengan peserta didik dan persiapannya baik dalam bentuk program semester maupun persiapan mengajar. ${ }^{6}$

Dari berbagai pengertian di atas maka dapat disimpulkan definisi konsep kinerja guru merupakan hasil pekerjaan atau prestasi kerja yang dilakukan oleh seorang guru berdasarkan kemampuan mengelola kegiatan belajar mengajar, yang meliputi perencanaan pembelajaran, pelaksanaan pembelajaran, dan evaluasi pembelajaran serta membina hubungan antar pribadi (interpersonal) dengan siswanya.

Menurut Kartono Kartini: 1985terdapat dua faktor yang mempengaruhi kinerja guru, pertama yaitu faktor kecerdasan, keterampilan, keterampilan, bakat, kemampuan, motivasi, kesehatan, kepribadian, cita-cita dan tujuan.Selanjutnya yang termasuk faktor yang berasal dari luar diri sendiri (ekstern), diantaranya pertama adalah keadaan lingkungan keluarga,lingkungan kerja, komunikasi, sarana dan prasarana. ${ }^{7}$ Jadi dapat disimpulkan bahwa faktor internal dan eksternal yang dimiliki seorang guru

\footnotetext{
${ }^{3}$ Riduwan, Metode dan Teknik Menyusun Proposal Penelitian untuk Mahasiswa S1, S2 \& S3. (Bandung: Alfabeta, 2009), h. 113.

${ }^{4}$ Dessler, G. Manajemen Personalia: Teknik \& konsep Modern. Alih Bahasa Oleh: Agus Dharma. (Jakarta: Penerbit Erlangga, 1997). h. 513.

${ }^{5}$ Kusmianto, Panduan Penilaian Kinerja Guru Oleh Pengawas. (Jakarta: , 1997). h. 49.

${ }^{6}$ Soedijarto, Memantapkan Kinerja Sistem Pendidikan Nasional.(Jakarta: Depdikbud, 1993), h. 35.

${ }^{7}$ Kartono kartini. Psikologi dalam dunia kerja. (Bandung: Alumni, 1981).
} 
mempengaruhi tinggi rendah kinerja yang dimilikinya.

\section{B. Metode Prompts}

Menurut Prompts Cooper, Heron, \& Heward adalah stimulus yang diberikan sebelum atau selama terjadinya perilaku. Fungsi dari prompts adalah membantu terjadinya perilaku yang diinginkan, sehingga siapapun yang melakukan perilaku tersebut bisa memperoleh penguatan. ${ }^{8}$ Prompts yang diberikan kepada anak berupa informasi penjelas atau bantuan yang memudahkan siswa untuk menjalankan sebuah intruksi. Prompts dibedakan menjadi 4 jenis diantaranya:

1. Verbal prompts adalah bentuk informasi verbal yang diberikan sebagai tambahan instruksi pada tugas yang akan dikerjakan oleh siswa. Hal ini digunakan untuk informasi mengenai bagaimana cara dia mengatasi tugasnya.

2. Gestural prompts, merupakan gerakan fisik atau gesture dari orang lain yang diharapkan dapat menghasilkan respon yang benar pada subjek. Dalam gestural informasi diberikan melalui gerak anggota tubuh.

3. Modeling prompts, dilakukan untuk memberikan informasi mengenai cara mengatasi tugasnya dengan cara mempraktekkan. Sehingga ia akan mencontoh dari apa yang kita kerjakan. Modelling dilakukan ketika verbal prompts tidak berhasil.

4. Physical prompts, merupakan sentuhan secara fisik dari orang lain kepada subjek untuk membantunya melakukan perilaku yang diinginkan secara benar. SulzerAzaroff dan Mayer mengemukakan bahwa physical prompts digunakan ketika verbal, gestural, dan modeling prompts belum dapat menghasilkan perilaku yang diinginkan secara tepat. Kontak fisik yang diberikan untuk membantu anak mengerjakan tugasnya. ${ }^{9}$

Keempat tipe response prompts memiliki keunggulan karena dapat membantu seseorang menghasilkan perilaku yang diinginkan secara tepat. Bagi siswa penyandang disabilitas A yang memiliki keterbatasan penglihatan metode tersebut membantu agar pesan atau materi pelajaran yang disampaikan dapat diterima/ditangkap oleh anak tunanetra melalui indera-indera yang masih berfungsi, yaitu indera pendengaran, perabaan, pengecapan, serta sisa penglihatan (bagi anak low vision).

\section{Penyandang Disabilitas A}

Disabilitas merupakan kata bahasa Indonesia yang berasal dari kata serapan bahasa Inggris disability (jamak: disabilities) yang berarti cacat atau ketidakmampuan. Disabilitas terbagi dalam beberapa jenis diantaranya ialah disabilitas A atau tunanetra. Menurut Bandi Delphi, tunanetra pada hakikatnya ialah kondisi dari mata atau penglihatan yang karena sesuatu hal tidak berfungsi sebagaimana mestinya. Sehingga

\footnotetext{
${ }^{8}$ Cooper, J. O., Heron, T. E., \& Heward, W. L. Applied Behavior Analysis (Chapters 19-22), (Upper Saddle River, NJ: Prentice-Hall, 1987), h. 312.

9 Sulzer, A. B., \& Mayer, G. R. Instructors Manual to accompanyBehavior analysis for lasting change, (Harcourt Brace: Fort Worth, TX, 1991).
} 
mengalami keterbatasan atau ketidakmampuan melihat. ${ }^{10}$ Klasifikasi tunanetra menurut Sidarta terbagi menjadi dua yaitu penglihatan lemah (low vision) dan Buta total (Totaly Blind). ${ }^{11}$ Menurut Mohammad Efendi ciri-ciri Anak Tunanetra jika ia memiliki virus sentralis 6/60 lebih kecil dari itu sehingga tidak mampu melihat, tidak mampu mengenali orang pada jarak 6 meter, kerusakan nyata pada kedua bola mata, sering merabaraba/tersandung waktu berjalan, mengalami kesulitan mengambil benda kecil di dekatnya, bagian bola mata yang hitam berwarna keruh/bersisik/kering, peradangan hebat pada kedua bola mata, mata bergoyang terus. ${ }^{12}$

\section{Hasil Observasi Pembelajaran}

Hasil observasi pembelajaran akan dipaparkan setiap jenis metode yang diteliti yaitu verbal, gestural, modeling danphysical promptsyang diterapkan Hasil observasi pembelajaran menggunakan metode prompts dan hasil belajar siswa pada materi thaharah, sholat dan BTQ.

\section{Verbalprompts}

Berdasarkan hasil observasi yang dilakukan, diperoleh bentuk penerapan verbal prompts ebagai berikut:

Tabel 2. Kinerja penerapan metode verbal prompts pada siswa Disabilitas A

\begin{tabular}{|c|c|c|c|c|c|c|}
\hline \multirow[b]{2}{*}{ Guru } & \multirow[b]{2}{*}{ Materi } & \multicolumn{5}{|c|}{ Verbal Prompts Indicators } \\
\hline & & Instruction & Rules & Remainder & Question & $\begin{array}{c}\text { Positive } \\
\text { Reinforcement }\end{array}$ \\
\hline \multirow[t]{4}{*}{ NH } & \multirow[t]{4}{*}{ Sholat } & $\begin{array}{l}\text { Tangan diangkat } \\
\text { selurus telinga }\end{array}$ & $\begin{array}{l}\text { Tidak } \\
\text { boleh } \\
\text { geleng- } \\
\text { geleng } \\
\text { kepala saat } \\
\text { sholat }\end{array}$ & $\begin{array}{l}\text { Jangan lupa } \\
\text { baca niat }\end{array}$ & $\begin{array}{l}\text { Gerakan apa } \\
\text { yang pertama } \\
\text { saat sholat? }\end{array}$ & $\begin{array}{l}\text { Yah bagus, } \\
\text { harus berurut } \\
\text { yah }\end{array}$ \\
\hline & & $\begin{array}{l}\text { Tangan kanan } \\
\text { diatas tangan kiri }\end{array}$ & $\begin{array}{l}\text { Tangan } \\
\text { lurus saat, } \\
\text { tidak } \\
\text { bengkok }\end{array}$ & $\begin{array}{l}\text { Telunjuk } \\
\text { diangkat }\end{array}$ & $\begin{array}{l}\text { Bagaimana } \\
\text { posisi } \\
\text { tangan? }\end{array}$ & $\begin{array}{l}\text { Iyaaa sudah } \\
\text { betul }\end{array}$ \\
\hline & & $\begin{array}{l}\text { Tangan } \\
\text { memegang } \\
\text { dilutut bukan di } \\
\text { paha }\end{array}$ & $\begin{array}{l}\text { Kaki } \\
\text { jangan } \\
\text { terlalu } \\
\text { lebar }\end{array}$ & & & \\
\hline & & Jari kaki kanan & Siku & & & \\
\hline
\end{tabular}

10 Delphi, Bandi, Pembelajaran anak berkebutuhan khusus dalam setting pendidikan inklusi.(Yogyakarta: KTSP, 2009). h. 15

${ }^{11}$ Ilyas, Sidarta, Ilmu Penyakit Mata. Edisi ketiga cetakan ke 6. (Jakarta: Balai Penerbit Fakultas Kedokteran Universitas Indonesia, 2009). h. 155.

${ }^{12}$ Efendi, Mohammad. Pengantar psikopedagogig anak berkelainan. (Jakarta: bumi aksara, 2008). h. 2 . 


\begin{tabular}{|c|c|c|c|c|c|c|}
\hline \multirow[b]{2}{*}{ Guru } & \multirow[b]{2}{*}{ Materi } & \multicolumn{5}{|c|}{ Verbal Prompts Indicators } \\
\hline & & Instruction & Rules & Remainder & Question & $\begin{array}{c}\text { Positive } \\
\text { Reinforcement }\end{array}$ \\
\hline & & $\begin{array}{l}\text { ditekuk yang kiri } \\
\text { diduduki saat } \\
\text { duduk }\end{array}$ & $\begin{array}{l}\text { diangkat, } \\
\text { telapak } \\
\text { tangan saja } \\
\text { yang } \\
\text { menyentuh } \\
\text { lantai saat } \\
\text { sujud. }\end{array}$ & & & \\
\hline \multirow[t]{3}{*}{ KS } & Thaharah & $\begin{array}{l}\text { Tempelkan ke } \\
\text { dinding, kedua } \\
\text { tangan }\end{array}$ & $\begin{array}{l}\text { Tangan } \\
\text { kanan } \\
\text { duluan } \\
\text { baru } \\
\text { tangan kiri }\end{array}$ & $\begin{array}{l}\text { Jangan lupa } \\
\text { pindah } \\
\text { tempat ambil } \\
\text { debu yang } \\
\text { masih suci }\end{array}$ & $\begin{array}{l}\text { Apa saja } \\
\text { yang di usap } \\
\text { saat } \\
\text { thaharah? }\end{array}$ & \\
\hline & & $\begin{array}{l}\text { Tangan kanan } \\
\text { diusap sampai ke } \\
\text { siku lanjut ke } \\
\text { arah depan lengan }\end{array}$ & $\begin{array}{l}\text { Ambil } \\
\text { debu baru } \\
\text { untuk } \\
\text { muka. }\end{array}$ & $\begin{array}{l}\text { Ingat harus } \\
\text { berurutan }\end{array}$ & & \\
\hline & & $\begin{array}{l}\text { Muka di usap } \\
\text { dari keningke } \\
\text { bawah pakai dua } \\
\text { tangan } \\
\text { bersamaan }\end{array}$ & & & & \\
\hline RM & BTQ & $\begin{array}{l}\text { Guru } \\
\text { menginstruksikan } \\
\text { penulisan huruf } \\
\text { hijaiyyah dan } \\
\text { syakal seperti: } \\
\grave{\imath}=\text { Titik } 1 \\
\varphi=\text { Titik } 1,2 \\
\text { Fathah = Titik } 2 \\
\text { Kasrah = Titik } \\
1,5\end{array}$ & & $\begin{array}{l}\text { Guru } \\
\text { mengingatkan } \\
\text { cara } \\
\text { membaca } \\
\text { ikhfa, } \\
\text { idgham, izhar } \\
\text { dan tajwid } \\
\text { lainnya }\end{array}$ & $\begin{array}{l}\text { Guru } \\
\text { menguji } \\
\text { dengan } \\
\text { menyebut } \\
\text { titik dan } \\
\text { siswa } \\
\text { menjawab } \\
\text { huruf dan } \\
\text { tanda } \\
\text { bacanya. } \\
\text { Contoh: } \\
\text { Guru: } \\
\text { “Titik 2,4,5 } \\
\text { adalah } \\
\text { huruf?” } \\
\text { "Huruf } \\
\text { خdalam } \\
\text { braille titik } \\
\text { berapa?” }\end{array}$ & $\begin{array}{l}\text { Yah benar, } \\
\text { latihan yang } \\
\text { banyak biar } \\
\text { tidak lupa nak } \\
\text { yah.. }\end{array}$ \\
\hline
\end{tabular}

Sumber data: Diolah dari instrtumen observasi pembelajaran prompts

Berdasarkan tabel 2 dapat diketahui bahwa setiap guru menggunakan metode verbal prompts pada pembelajarannya dengan jumlah indikator yang digunakan berbeda. 
Guru NH menggunakan semua indikator verbal prompts sedangkan guru KS dan RM hanya menggunakan 4 dari 5 indikator verbal prompts yaitu guru KS menggunakan instruction, ruler, reminder, question dan tidak menggunakan positive instruction selanjutnya Guru RM menggunakan instruction, reminder, question,positive instruction dan tidak menggunakan ruler.

\section{Gestural prompts}

Berdasarkan hasil observasi yang dilakukan, diperoleh diperoleh bentuk penerapan gestural prompt sebagai berikut:

Tabel 3. Kinerja penerapan metode gestural prompts pada siswa Disabilitas A

\begin{tabular}{|c|c|c|c|}
\hline \multirow{2}{*}{ GURU } & \multirow{2}{*}{ MATERI } & \multicolumn{2}{|c|}{ Gestural Prompts Indicators } \\
\hline & & Gerakan & Catatan \\
\hline $\mathrm{NH}$ & Sholat & $\begin{array}{l}\text { Guru mengangkat } \\
\text { tangan berulang-ulang }\end{array}$ & $\begin{array}{l}\text { Pemberian hanya pada siswa low } \\
\text { vision (masih ada sisa penglihatan) }\end{array}$ \\
\hline KS & Thaharah & - & - \\
\hline $\mathrm{RM}$ & BTQ & - & - \\
\hline
\end{tabular}

Sumber data: Diolah dari instrtumen observasi pembelajaran prompts

Berdasarkan tabel 3 diatas dapat diketahui bahwa hanya seorang guru yang menggunakan metode gestural prompts yaitu guru NH. Penggunaan metode inipun hanya diberikan pada siswa yang low vision atau siswa yang masih memiliki sisa penglihatan.

\section{Modeling prompts}

Berdasarkan hasil observasi yang dilakukan, diperoleh bentuk penerapan Modeling prompt sebagai berikut:

Tabel 4. Kinerja penerapan metode modeling prompts pada siswa Disabilitas A

\begin{tabular}{|c|c|c|c|c|}
\hline \multirow{2}{*}{ Guru } & \multirow{2}{*}{ Materi } & \multicolumn{3}{|c|}{ Modeling Prompts Indicators } \\
\hline & & Demonstrasi & Pemodelan Sebaya & Pemodelan Guru \\
\hline $\mathrm{NH}$ & Sholat & - & $\begin{array}{l}\text { Guru memanggil seorang } \\
\text { siswa dan mengarahkan ke } \\
\text { posisi tertentu (takbir, ruku, } \\
\text { sujud, tahiyat) dan } \\
\text { selanjutnya memanggil } \\
\text { siswa untuk dipandu oleh } \\
\text { guru untuk meraba posisi } \\
\text { tubuh rekannya dengan } \\
\text { tujuan mengetahui posisi } \\
\text { tubuh pada setiap gerakan } \\
\text { sholat. }\end{array}$ & $\begin{array}{l}\text { Guru memandu } \\
\text { siswa untuk } \\
\text { meraba posisi } \\
\text { telunjuknya untuk } \\
\text { posisi tahiyat. }\end{array}$ \\
\hline KS & Thaharah & - & - & - \\
\hline RM & BTQ & Guru membaca & Guru menginstruksikan & Guru membaca \\
\hline
\end{tabular}




\begin{tabular}{|c|c|c|c|c|}
\hline & & $\begin{array}{l}\text { ayat Qur'an dan } \\
\text { di ikuti oleh siswa } \\
\text { bersama-sama. }\end{array}$ & $\begin{array}{l}\text { seorang siswa untuk } \\
\text { membaca ayat Qur'an dan } \\
\text { rekan yang lainnya } \\
\text { mengoreksi jika ada } \\
\text { kesalahan. }\end{array}$ & $\begin{array}{l}\text { ayat Qur'an dan } \\
\text { siswa yang } \\
\text { menulis huruf } \\
\text { dalam Qur'an } \\
\text { braille }\end{array}$ \\
\hline & & $\begin{array}{l}\text { Siswa membaca } \\
\text { ayat Qur'an }\end{array}$ & $\begin{array}{l}\text { Guru menginstruksikan } \\
\text { siswa untuk mencontohkan } \\
\text { suatu bacaan untuk } \\
\text { dikoreksi tajwidnya }\end{array}$ & $\begin{array}{l}\text { Guru membaca } \\
\text { ayat Qur'an dan } \\
\text { siswa yang } \\
\text { menyebutkan jenis } \\
\text { tajwidnya. }\end{array}$ \\
\hline
\end{tabular}

Sumber data: Diolah dari instrtumen observasi pembelajaran prompts

Berdasarkan tabel 4 diatas dapat diketahui bahwa guru NH hanya menggunakan 3 dari 4 indikator modeling prompts, guru KS tidak menggunakan metode modeling prompts sama sekali dan guru RM menggunakan semua indikator metode modeling prompts.

\section{Physical prompts}

Berdasarkan hasil observasi yang dilakukan, diperoleh bentuk penerapan Physical promptsebagai berikut:

Tabel 5. Kinerja penerapan metode physical prompts pada siswa Disabilitas A

\begin{tabular}{|c|c|c|c|}
\hline \multirow{2}{*}{ Guru } & \multirow{2}{*}{ Materi } & \multicolumn{2}{|r|}{ Physical Prompts Indicators } \\
\hline & & Stimulus & Bentuk \\
\hline \multirow[t]{7}{*}{ NH } & \multirow[t]{4}{*}{ Sholat } & \multirow[t]{4}{*}{ Sentuhan } & $\begin{array}{l}\text { Guru mengangkat siku siswa agar telapak tangannya selurus } \\
\text { dengan telinga. }\end{array}$ \\
\hline & & & Guru menepuk kaki siswa untuk membenarkan posisi berdiri. \\
\hline & & & $\begin{array}{l}\text { Guru membenarkan posisi lengan dengan menegakkan/ } \\
\text { meluruskan tangan ke arah lutut. }\end{array}$ \\
\hline & & & Guru membenarkan posisi telapak tangan dan siku saat sujud \\
\hline & & \multirow[t]{3}{*}{ Menggerakkan } & $\begin{array}{l}\text { Guru menggerakkan kedua tangan siswa untuk membenarkan } \\
\text { posisi takbir dan selanjutnya meletakkan dengan tangan kanan } \\
\text { diatas tangan kiri. }\end{array}$ \\
\hline & & & $\begin{array}{l}\text { Guru Menggerakkan jari-jari kaki kanan untuk berdiri saat posisi } \\
\text { duduk diantara } 2 \text { sujud ataupun tahiat. }\end{array}$ \\
\hline & & & Guru menggerakkan kepala siswa saat salam dengan berlahan. \\
\hline KS & Thaharah & Sentuhan & $\begin{array}{l}\text { Guru menggerakkan dan memandu siswa dalam melakukan } \\
\text { gerakan thaharah seperti mendapatkan debu suci, mengusap } \\
\text { kedua tangan sampai siku dengan benar dan mengusap wajah. }\end{array}$ \\
\hline RM & BTQ & Sentuhan & $\begin{array}{l}\text { Guru membimbing siswa untuk meraba al qur'an braille dan } \\
\text { menjelaskan mengenai bacaan dan tajwidnya. }\end{array}$ \\
\hline
\end{tabular}

Sumber data: Diolah dari instrtumen observasi pembelajaranprompts

Berdasarkan tabel 5 diatas dapat diketahui bahwa semua guru menggunakan metode physical prompts tanpa terkecuali. Bentuk stimulus yang digunakan guru ialah sentuhan dan gerakan (kontak fisik). 
Berdasarkan hasil observasi diatas maka tingkat kinerja guru PAI dalam penerapan metode prompts dapat dilihat pada tabel berikut:

Tabel 6. Kinerja penerapan metode physical prompts pada siswa Disabilitas A

\begin{tabular}{|l|c|c|c|c|c|l|}
\hline \multicolumn{1}{|c|}{ Guru } & Verbal & Gestural & Modeling & Physical & Skor & \multicolumn{1}{c|}{ Tingkat } \\
\hline NH & $\sqrt{ }$ & $\sqrt{ }$ & $\sqrt{ }$ & $\sqrt{ }$ & 4 & Sangat Tinggi \\
\hline KS & $\sqrt{ }$ & - & - & $\sqrt{ }$ & 2 & Sedang \\
\hline RM & $\sqrt{ }$ & - & $\sqrt{ }$ & $\sqrt{ }$ & 3 & Tinggi \\
\hline
\end{tabular}

Sumber data: Diolah dari observasi pembelajaran prompts

Berdasarkan tabel 6, dapat diperoleh bahwa tinggkat kinerja guru PAI berada pada tingkat yang bervariasi yaitu sedang, tinggi dan sangat tinggi. Guru NH memiliki kinerja pada skor 4 atau sangat tinggi yang berarti menerapkan semua jenis prompt dalam pembelajaran PAI. Guru RM memiliki kinerja pada skor 3 atau tinggi yang menerapkan 3 promptsedangkan guru KS berada pada skor 2 atau tingkat sedang yang hanya menerapkan dua jenis prompt yaitu verbal dan physical prompts saja.

\section{B. Pembahasan}

Berdasarkan hasil penelitian yang telah diuraikan dapat diperoleh bahwa dalam pembelajaran PAI di Sekolah SLB A Yapti Makassar telah diterapkan metode prompts. Guru PAI dalam proses pembelajaran menerapkan metode promptsdengan tingkat penggunaan yang bervariasi baik dari segi jenis maupun indikator setiap metode prompts. Penggunaan jenis dan indikator yang berbeda disebabkan oleh beberapa faktor diantaranya:

\section{Faktor Materi Ajar}

Perbedaan penggunaan jenis dan indikator metode prompts pada siswa tunanetra dipengaruhi oleh materi yang akan diajarkan, misalnya pada penggunaan metode verbal prompts guru RM tidak menggunakan indikator rule karena pada materi BTQ untuk aturan menulis dan membaca telah terjabarkan pada indikator instruction, hal ini sesuai pernyataan ibu RM bahwa larangan ataupun aturan dalam membaca qur'an braille diajarkan bersamaan dengan tatacara membaca dan menulisnya, tidak terpisah. (wawancara: Rahmawati, 2018). ${ }^{13}$ Hal yang sama ditunjukan oleh guru NH dan KS yang tidak menggunakan indikator demonstrasi pada metode modeling promptsuntuk materi sholat dan thaharah karena materi yang melibatkan gerakantanpa kontak fisik harus diajarkan pada siswa yang memiliki visual yang baik sedangkan siswa yang dihadapi adalah siswa penyandang disabilitas netra atau keterbatasan visual. Hal ini sesuai dengan pernyataan guru NH "Siswa yang kami hadapi, memiliki keterbatasan visual jadi tidak memungkinkan atau tidak cocok untuk materi yang ada gerakan menggunakan modeling prompts yang mendemonstrasikan dan memberikan contoh secara langsung ke siswa

\footnotetext{
${ }^{13}$ Rahmawati, Guru SLB A Yapti, "Wawancara”, pada tanggal 08 Mei 2018, di ruang kelas SLB A Yapti Makassar.
} 
tanpa ada sentuhan" (wawancara: Nurhayati, 2018). ${ }^{14}$

\section{Faktor Karakteristik siswa}

Selain faktor materi ajar, perbedaan penggunaan jenis dan indikator metode prompts pada siswa penyandang disabilitas A juga dipengaruhi oleh faktor karakteristik siswa. Pada penggunaan metode gestural hanya diterapkan oleh guru NH dan 2 guru lainnya tidak menerapkan karena siswa yang dihadapi oleh guru NH masih memiliki sisa penglihatan atau lowvision sedangkan siswa yang dihapi oleh guru KS dan RM memiliki karakteristik totaly blind atau buta total. Dengan karakteristik yang dimiliki oleh siswa menjadi pertimbangan bagi guru SLB A Yapti dalam menggunakan suatu metode. Hal ini sesuai dengan pernyataan guru NH bahwa "Mengajar anak dengan keterbatasan penglihatan tidak cocok memakai metode yang menggunakan bantuan dalam bentuk isyarat visual atau gerakan tubuh lainnya yang tidak bisa dilihat oleh siswa". ${ }^{15}$

\section{Faktor karakteristik Guru}

Karakteristik guru dalam hal ini Keterbatasan fisik yang dimiliki oleh guru juga mempengaruhi penerapan jenis dan metode prompts pada pembelajaran PAI di SLB A Yapti Makassar. Hal ini terlihat pada guru KS yang memiliki tingkat kinerja yang hanya berada pada tingkat sedang atau hanya menggunakan 2 (dua) jenis prompts saja. Kinerja guru KS ini dipengaruhi oleh karakteristik yang dimiliki yaitu keterbatasan visual atau tunanetra. Keterbatasan visual pada guru KS tidak memungkinkan untuk digunakan motode gestural dan modeling prompts yang menekankan untuk transfer informasi secara visual. Dalam wawancara yang dilakukan guru KS menyatakan bahwa "Bagaimana bisa di demonstrasikan atau hanya pakai isyarat sementara baik saya maupun siswa sama-sama tidak bisa melihat, sedangkan untuk materi yang melibatkan gerakan harus diraba karena tidak bisa dilihat". (wawancara: Kasmir, 2018)

\section{KESIMPULAN}

Adapun simpulan yang dapat ditarik berdasarkan uraian yang telah dipaparkan adalah sebagai berikut:

1. Tinggkat kinerja guru PAI berada pada tingkat yang bervariasi yaitu sedang, tinggi dan sangat tinggi. Guru NH memiliki kinerja pada skor 4 atau sangat tinggi yang berarti menerapkan semua jenis prompt dalam pembelajaran PAI. Guru RM memiliki kinerja pada skor 3 atau berada pada tingkat tinggi yang menerapkan 3 prompt sedangkan guru KS berada pada skor 2 atau tingkat sedang yang hanya menerapkan dua jenis prompt yaitu verbal dan physical prompts saja.

2. Perbedaan Penggunaan jenis dan indikator yang diterapkan oleh guru PAI berbeda disebabkan oleh 3 (tiga) faktor yaitu faktor materi ajar, faktor karakteristik siswa dan

${ }^{14}$ Nurhayati, Guru SLB A Yapti, "Wawancara”, pada tanggal 05 Mei 2018, di ruang Centre Braillo SLB A Yapti Makassar.

${ }^{15}$ Kasmir, Guru SLB A Yapti , "Wawancara”, pada tanggal 12 Mei 2018, di ruang Centre Braillo SLB A Yapti Makassar. 
faktor karakteristik guru.

\section{DAFTAR PUSTAKA}

Cooper, J. O., Heron, T. E., \& Heward, W. L. Applied Behavior Analysis (Chapters 1922), (Upper Saddle River, NJ: Prentice-Hall, 1987)

Delphi, Bandi, Pembelajaran anak berkebutuhan khusus dalam setting pendidikan inklusi.(Yogyakarta: KTSP, 2009)

Departemen Agama RI, Alquran dan Terjemahnya, (Jakarta: Institut Ilmu al Qur'an)

Departemen Pendidikan Nasional. Penilaian Kinerja Guru. (Jakarta: Direktorat Jenderal Peningkatan Mutu Pendidik dan Tenaga Kependidikan, 2008).

Dessler, G. Manajemen Personalia: Teknik \& konsep Modern. Alih Bahasa Oleh: Agus Dharma. (Jakarta: Penerbit Erlangga, 1997).

Efendi,Mohammad. Psikopedagogig anak berkelainan. (Jakarta: bumi aksara, 2008).

Ilyas, Sidarta, Ilmu Penyakit Mata. Edisi ketiga cetakan ke 6. (Jakarta : Balai Penerbit Fakultas Kedokteran Universitas Indonesia, 2009).

Kartono kartini. Psikologi dalam dunia kerja. (Bandung: Alumni, 1981).

Kasmir, Guru SLB A Yapti , "Wawancara”, pada tanggal 12 Mei 2018, di ruang Centre Braillo SLB A Yapti Makassar

Kusmianto, Panduan Penilaian Kinerja Guru Oleh Pengawas. (Jakarta: Erlangga, 1997).

Nurhayati, Guru SLB A Yapti, “Wawancara”, pada tanggal 05 Mei 2018, di ruang Centre Braillo SLB A Yapti Makassar.

Rahmawati, Guru SLB A Yapti , "Wawancara”, pada tanggal 08 Mei 2018, di ruang kelas SLB A Yapti Makassar.

Riduwan, Metode dan Teknik Menyusun Proposal Penelitian untuk Mahasiswa S1, S2 \& S3. (Bandung: Alfabeta, 2009)

Soedijarto, Memantapkan Kinerja Sistem Pendidikan Nasional.(Jakarta: Depdikbud, 1993)

Somantri Sutjihati,Psikologi Anak Luar Biasa,(Bandung: PT Refika Aditama, 2012)

Sulzer, A. B., \& Mayer, G. R. Instructors Manual to accompanyBehavior analysis for lasting change,(Harcourt Brace: Fort Worth, TX, 1991). 